\title{
Micronutrient intakes in Irish teenagers (13-17 years)
}

\author{
E. Hayes, J. Walton, E. M. Hannon and A. Flynn \\ Department of Food and Nutritional Science, University College Cork, Cork, Republic of Ireland
}

The objective of the present study was to estimate micronutrient intakes and the contribution of different food groups to micronutrient intakes in Irish teenagers. The prevalence of inadequacy of micronutrients was also assessed. Analysis was based on The National Teens Food Survey, which was carried out between September 2005 and September 2006 to establish a database of habitual food and drink consumption in a representative sample of Irish teenagers aged 13-17 years. A $7 \mathrm{~d}$ semi-weighed food record was used to collect food intake data from 441 teenagers (224 males, 217 females). Analysis of dietary intake data was carried out using WISPC (Tinuviel Software, Llanfechell, Anglesey, UK), which is based on McCance and Widdowson's The Composition of Foods, Sixth Edition ${ }^{(1)}$.

The mean intakes and the percentage with inadequate intakes of selected micronutrients are shown in Table 1 and the main food groups contributing to these intakes are shown in Table 2 . The percentage with mean daily intakes below the estimated average requirement ${ }^{(2)}$ for selected micronutrients is reported as an estimate of the prevalence of inadequate intakes ${ }^{(3)}$.

Table 1. Average intakes and the percentage with inadequacy of micronutrients for Irish teenagers

\begin{tabular}{|c|c|c|c|c|c|c|}
\hline \multirow[b]{2}{*}{ Micronutrient } & \multicolumn{3}{|c|}{ Males (n 224) } & \multicolumn{3}{|c|}{ Females ( $n$ 217) } \\
\hline & Mean & SD & Inadequacy $(\%)$ & Mean & $\mathrm{SD}$ & Inadequacy $(\%)$ \\
\hline $\mathrm{Ca}(\mathrm{mg})$ & 1070 & 409 & 23 & 738 & 328 & 42 \\
\hline $\mathrm{Fe}(\mathrm{mg})$ & 14 & 12 & 19 & 11 & 12 & 72 \\
\hline Vitamin A $(\mu \mathrm{g})$ & 901 & 601 & 25 & 686 & 441 & 31 \\
\hline Thiamin (mg) & 2 & 2 & 0 & 2 & 3 & 1 \\
\hline Riboflavin (mg) & 3 & 3 & 6 & 2 & 3 & 23 \\
\hline Vitamin $\mathrm{B}_{12}(\mu \mathrm{g})$ & 6 & 3 & 0 & 4 & 3 & 5 \\
\hline Folate $(\mu \mathrm{g})$ & 320 & 157 & 5 & 230 & 129 & 29 \\
\hline Vitamin C (mg) & 98 & 87 & 6 & 92 & 100 & 7 \\
\hline
\end{tabular}

When under-reporters were excluded (males: $63 \%$; females: $64 \%$ ), the $\%$ SEAR decreased (males: $6,2,16$ for calcium, iron, vitamin A; females: 15, 60, 10, 3, 9 for calcium, iron, vitamin A, riboflavin and folate).

Table 2. Main food groups contributing to micronutrient intakes of 441 Irish teenagers

\begin{tabular}{ll}
\hline Micronutrient & Main food groups and their percentage contribution \\
\hline $\mathrm{Ca}$ & Milk and yoghurt, 33; bread and rolls, 18 \\
$\mathrm{Fe}$ & Breakfast cereals, 23; meat and meat products, 17; bread and rolls, 16 \\
Vitamin A & Vegetables and vegetable dishes, 27; milk and yoghurt, 15; meat and meat products, 11 \\
Thiamin & Breakfast cereals, 20; meat and meat products, 19 \\
Riboflavin & Milk and yoghurt, 29; breakfast cereals, 19 \\
Vitamin $\mathrm{B}_{12}$ & Milk and yoghurt, 40; meat and meat products, 26 \\
Folate & Breakfast cereals, 20; potatoes and potato products, 16; bread and rolls, 12 \\
Vitamin $\mathrm{C}$ & Fruit and fruit juices, 33; potatoes and potato products, 19; vegetables and vegetable dishes, 10 \\
\hline
\end{tabular}

A significant prevalence of inadequate intakes was observed for $\mathrm{Ca}, \mathrm{Fe}$, vitamin $\mathrm{A}$ and folate, particularly in females.

The project was funded by the Irish Government under the National Development Plan 2000-2006.

1. Food Standards Agency (2002) McCance \& Widdowson's The Composition of Foods, Sixth Edition. Cambridge: Royal Society of Chemistry.

2. Department of Health UK (1991) Dietary Reference Values of Food Energy and Nutrients for the United Kingdom. Report on Health and Social Subjects no. 41. London: H. M. Stationery Office.

3. Carriquiry AL (1999) Public Health Nutr 2, 23-33. 